$$
\begin{aligned}
& \text { درجة تجمهيع الميانات وأثر ها } \\
& \text { على استقر ار إلعلاقاث الدالية }
\end{aligned}
$$

$$
\begin{aligned}
& \text { دكثود / فتحى خليل الخضر اوى" } \\
& \text { دكتور / بول ديفولد جونسون }
\end{aligned}
$$

* * * *محة طنطا وجامعة ولاية كارولينا الثشالية 


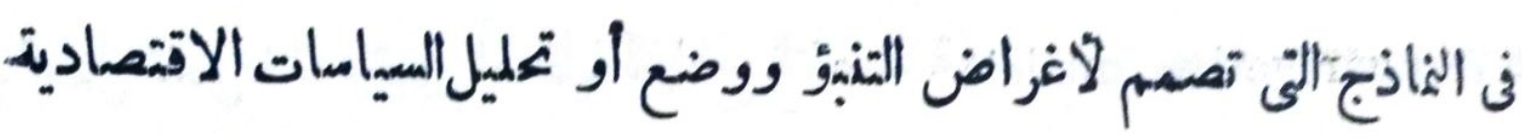

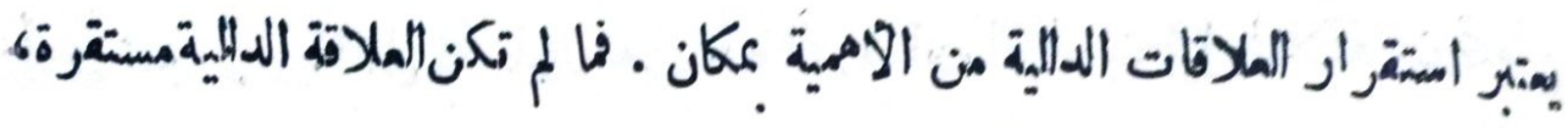
Sampling Period فإن أنة محاولة لاستخددامها فى الثنبو خارج نطاقفترة المائماينة سوف تأتى بتنبو ات لا تمت للواقع بصلة خاصـة إذا حدث عدم الاستقرار قرب نهاية فترة المهايةـــة ـ ومن زاحية أخرى ، إذا شهدت الميانات عن فترة حديثة

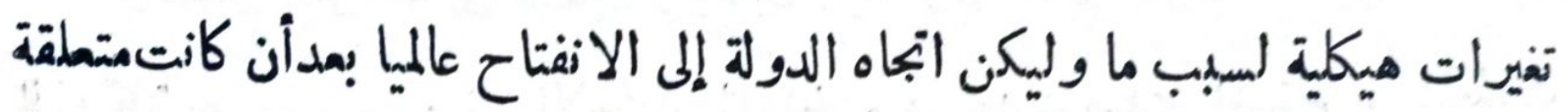
اقتصاديا ، فإن أنة مدلمات Paraureters يتم تقديرها أحصائيا باستخدام بيانات عن فـترة ماقبل حدوث هـذه التخييرات قد لاتصـلمح لوضع أو تملميل السياساث الاقتصادية التى تستهدف علاج المشاكل الحالية لمتزان المدفوعات .

هن هما تبدوا أهمية الاختمجارات المستخدمة في الكشف عن استقرار أو عدم

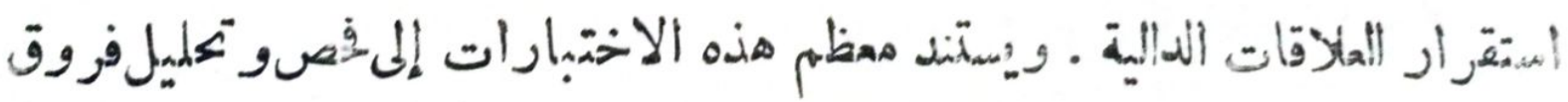

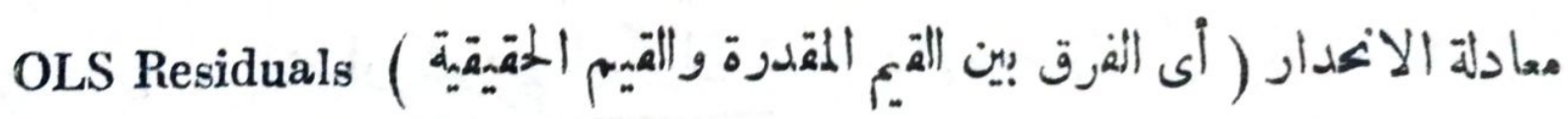

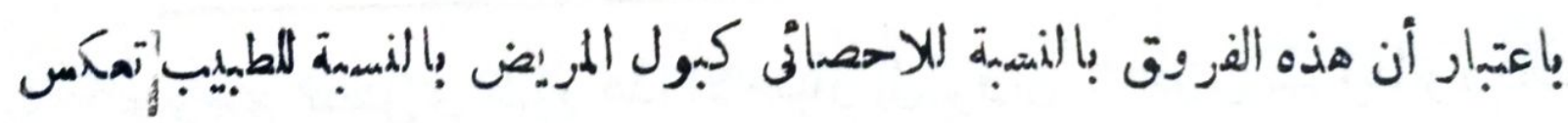
كل ما يهترى الوضع من تغيرات . وأهم هذه الاختبارات ، وهو ماتستخدمه هذه

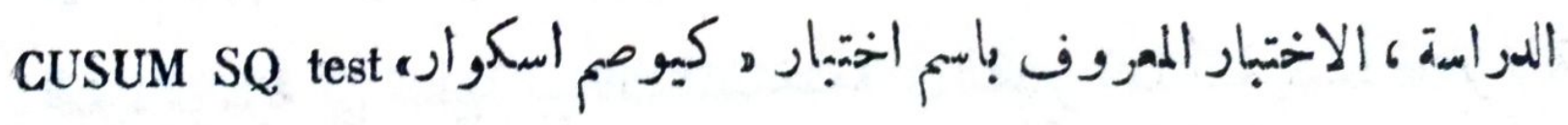

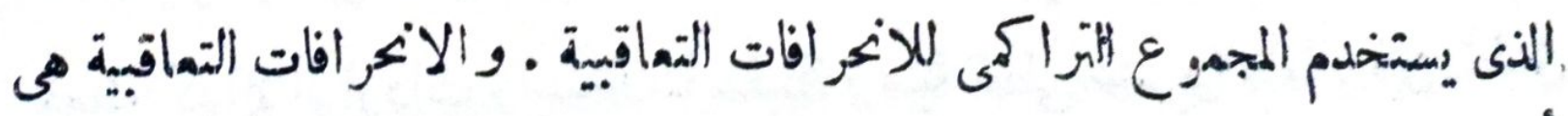

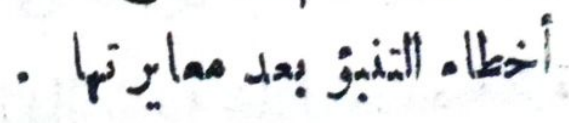

Recursive residuals are normalized one - peroid ahead forecasting errors

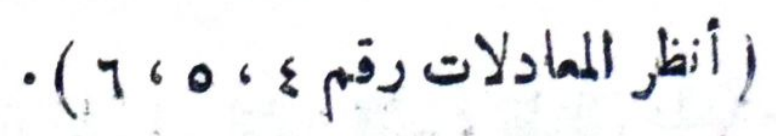


ولكن يلاحظ على الدراسات التى تناولت قضية الاستقراد فيلاقلاقات الدالية

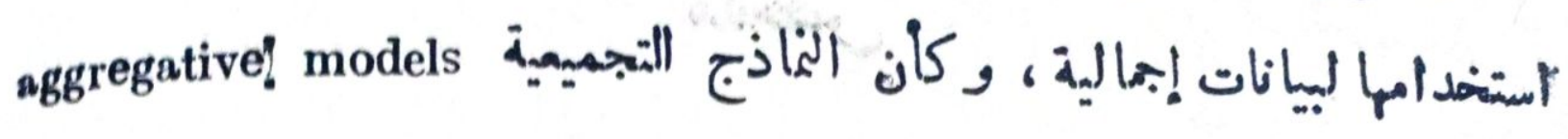

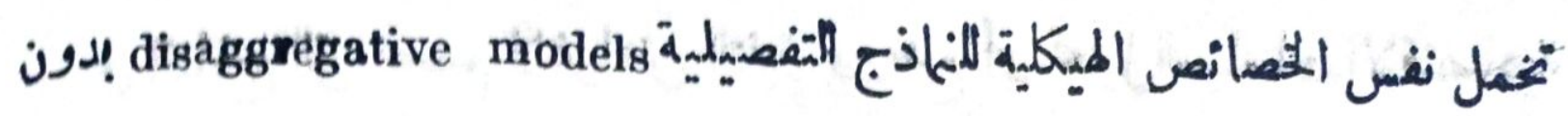
أدنى نمييد ـ. وبالنالى لم تحاول هــــذه الدراسات القيام بتحليل الملاقة بين تجميع المانات data aggregation وسلوك المهلهات المقدره خلال فترة المعاينة ،وهذا

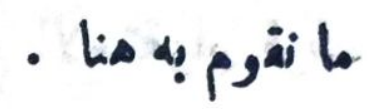

و تنقسم الدراسة إلى قسمين رنيمبين : يتناول القبم الأول التهليل الفظرى المشكلة حيث يتم وصف الاختبار المستخدم في تحديد مسدى استمقرار المملات المقدرة ، ويلى ذلك تحليل لأر التجميع سواء الزهنى Temporal Aggregation

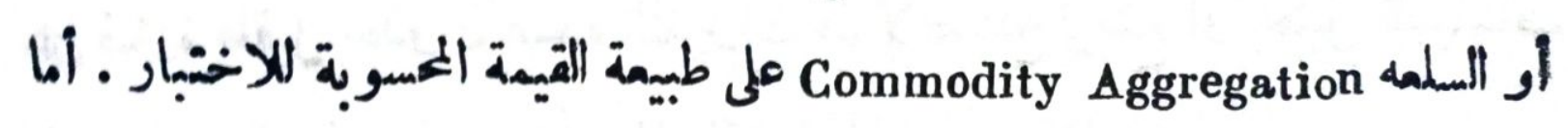
القسم الثانى فيبدأ باستهر اض المّهوذج المستخدم فى التطبيق ، ولامنتانج التجـريبية

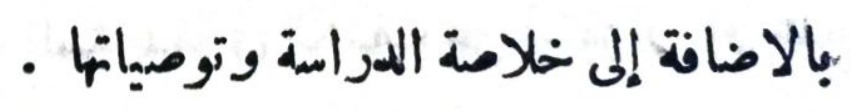

$$
\text { : إختبار كيوصم اسكوار }
$$

وبوجع الفضل فن ظهور هذا الاختمبار إلى بروان - دربن - ايفانز وذلك

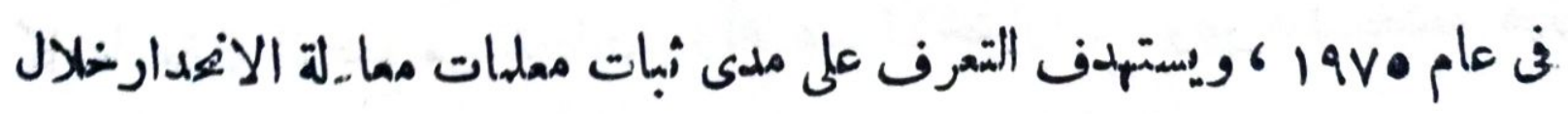

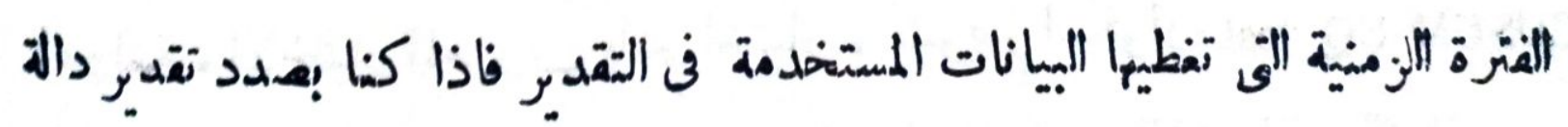
مهينة كدالة الواردات وامتخخدمنا سلمسلة زمنية تغطى عشرين عاما ، فإن تطيق

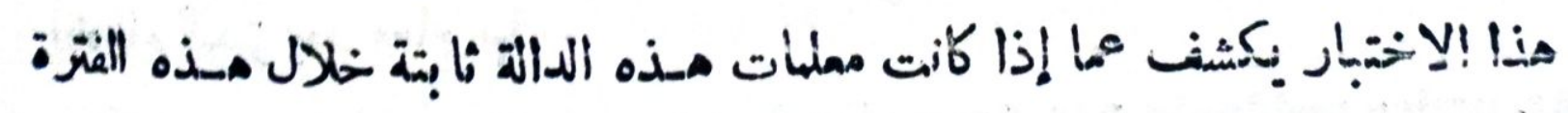
- الم تغيزت

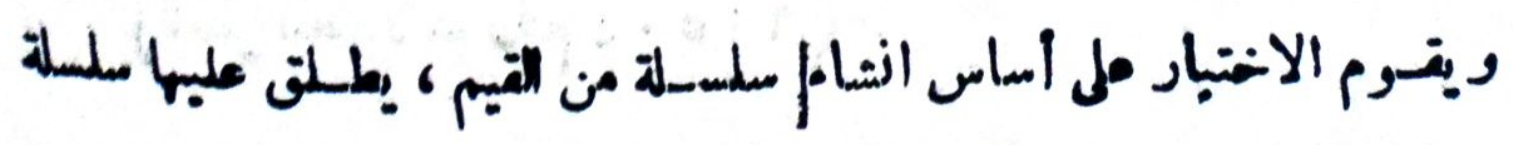




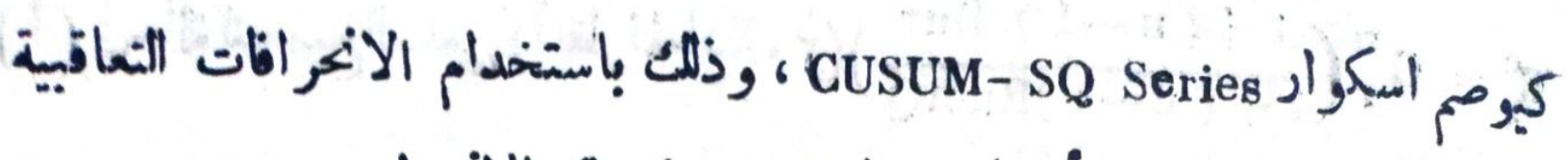

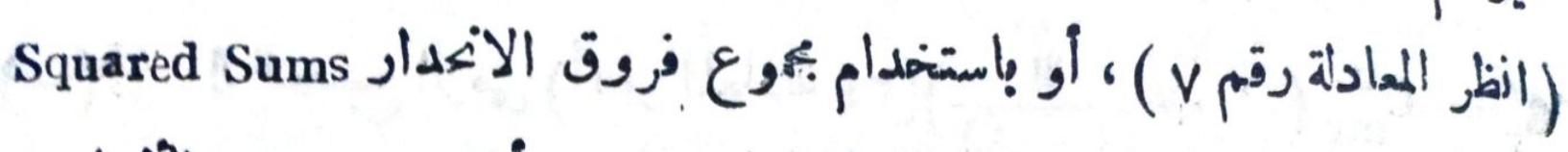
of Regression Residuals

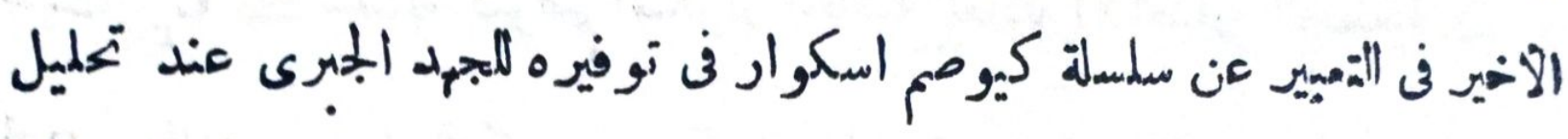

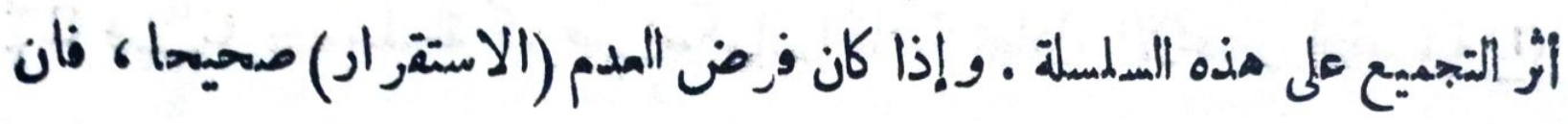

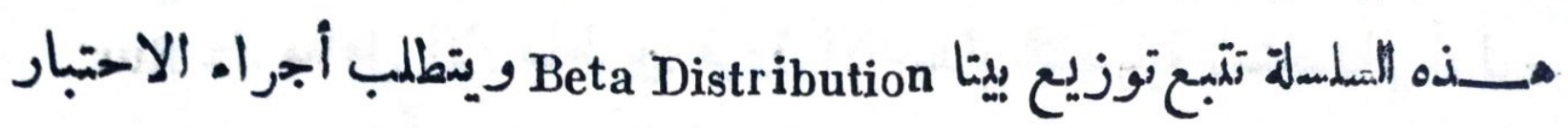

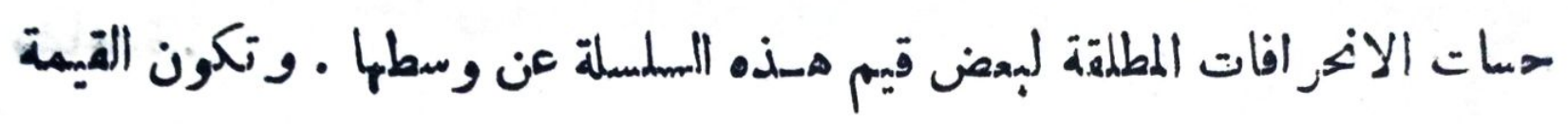

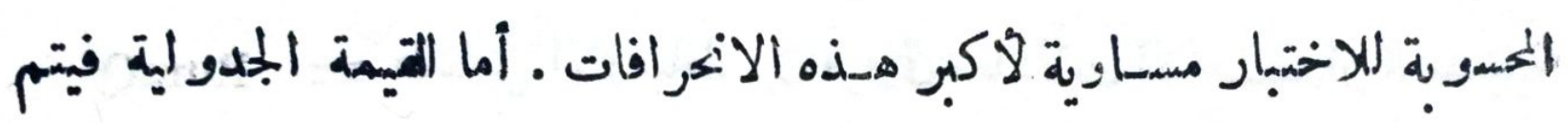

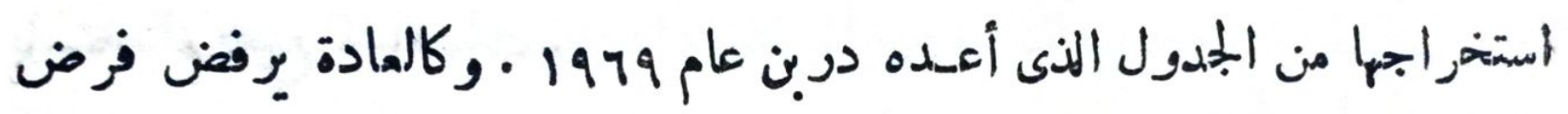

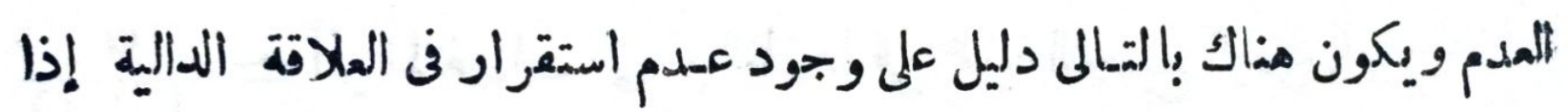

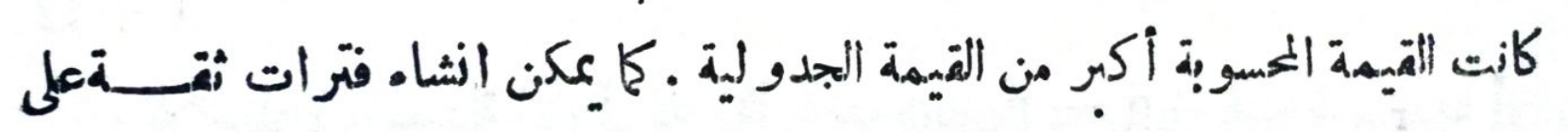
اللهجو المبين بالصفحة الخامسة .

$$
\text { : و (r) }
$$

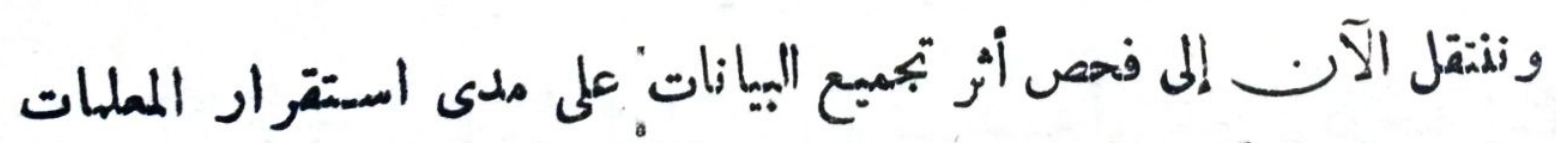

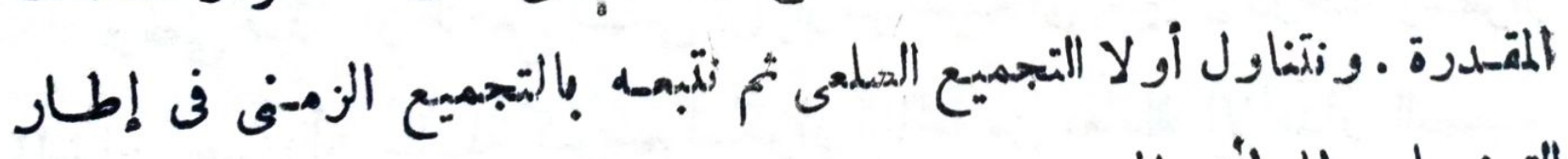

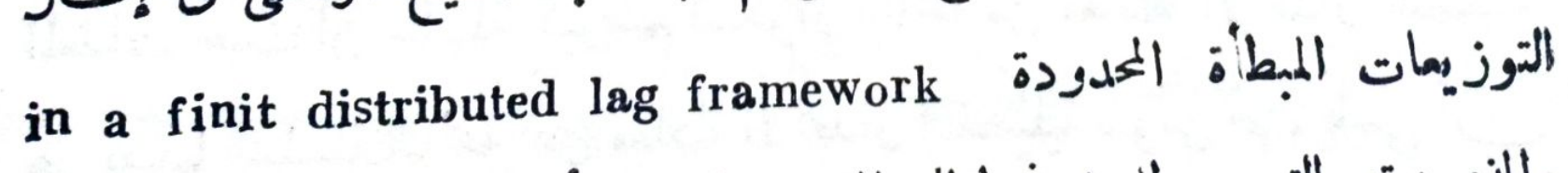

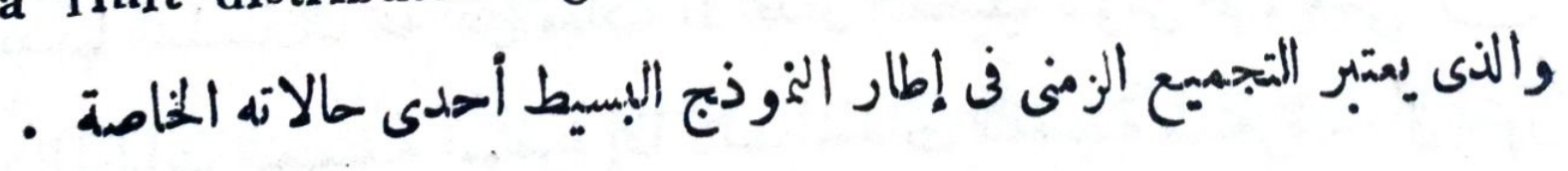
ويقوم منج "لمهث فن هذا الجز • على محارلة التهبير عن سلسلة كبوصماسكوار

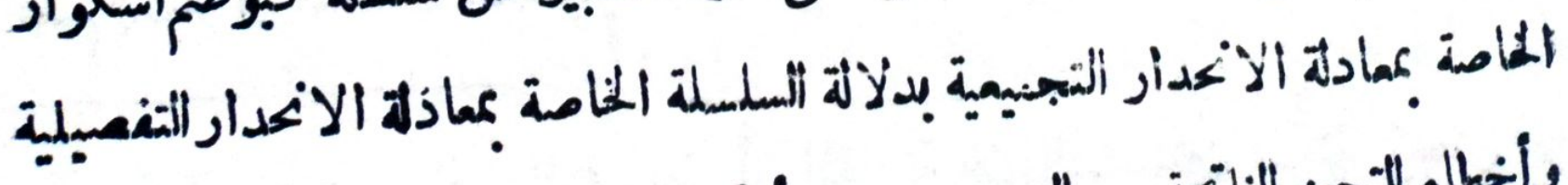

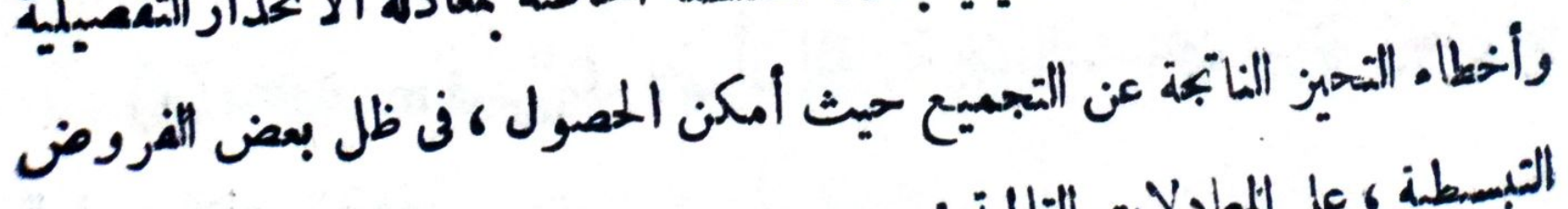




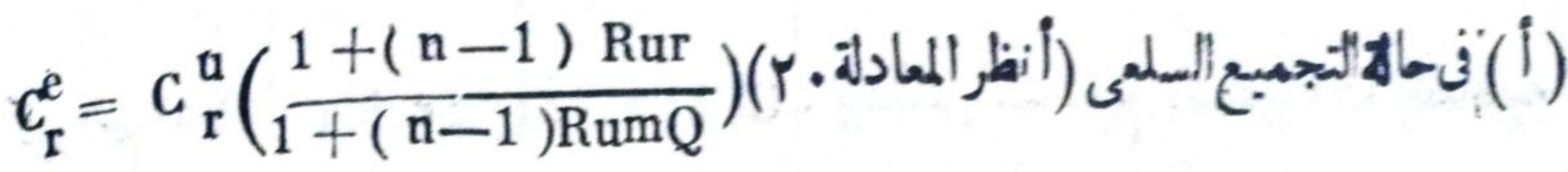
$c_{\mathrm{r}}^{\mathrm{e}}=\mathrm{C}_{\mathrm{mr}}^{\mathrm{u}}\left(1+\frac{\Psi}{1+\Omega}\right)(\mathrm{r}$ (ب) حبث C C

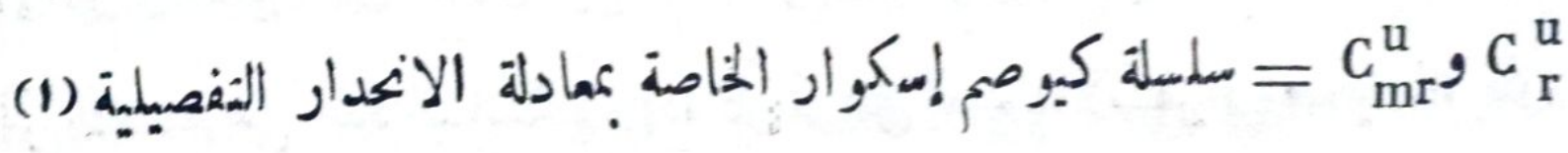

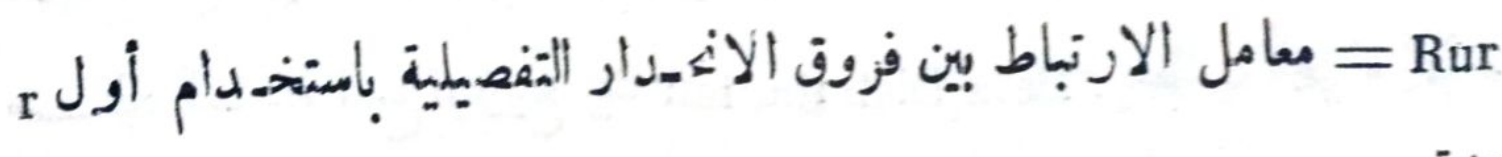
مشاهدة.

= RumQ

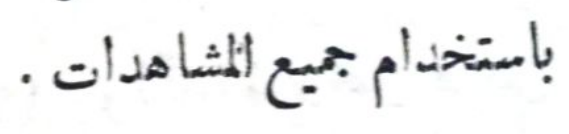

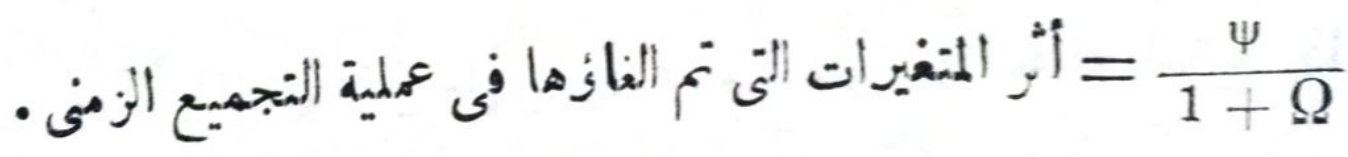

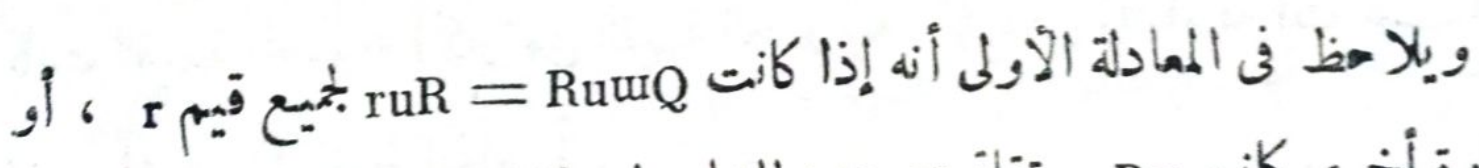

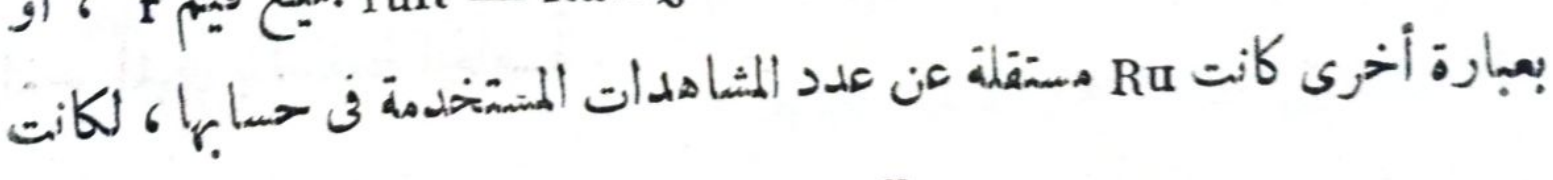

$$
\mathrm{c}_{\mathrm{r}}^{\mathrm{e}}=\mathrm{c}_{\mathrm{r}}^{\mathrm{u}}
$$

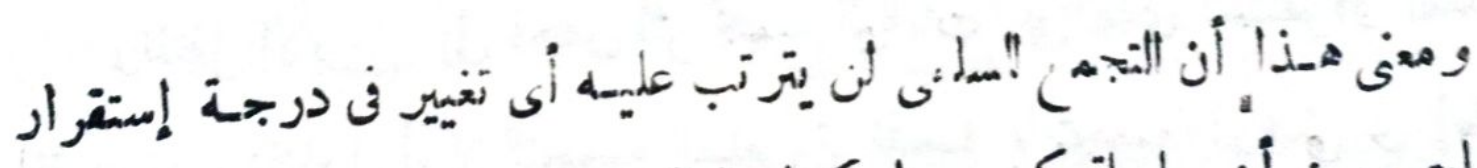

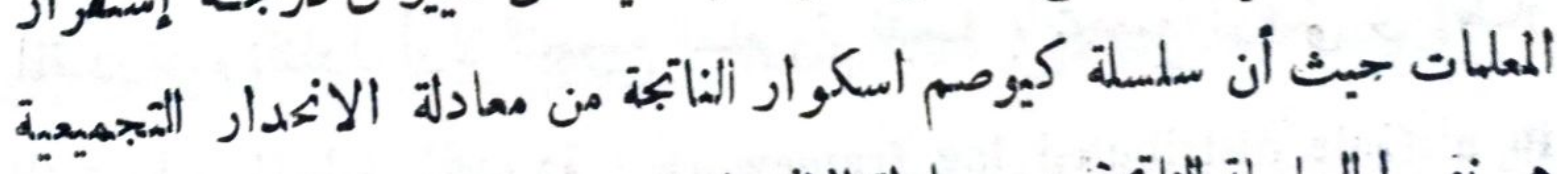

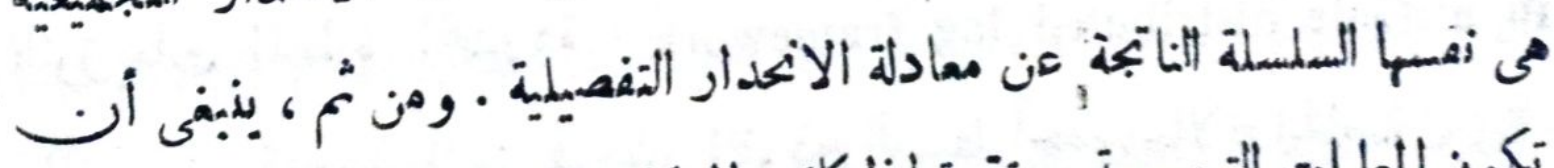

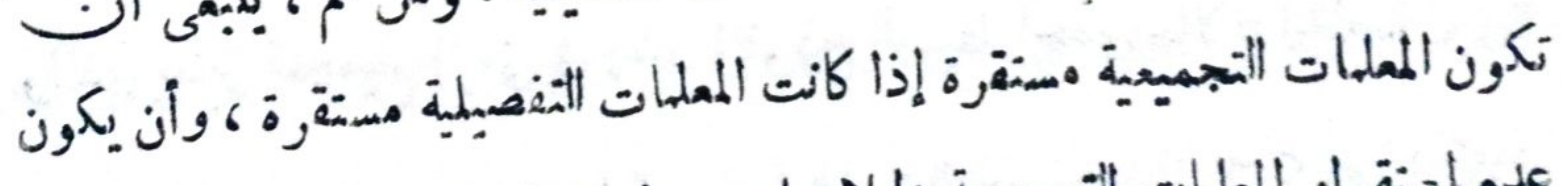

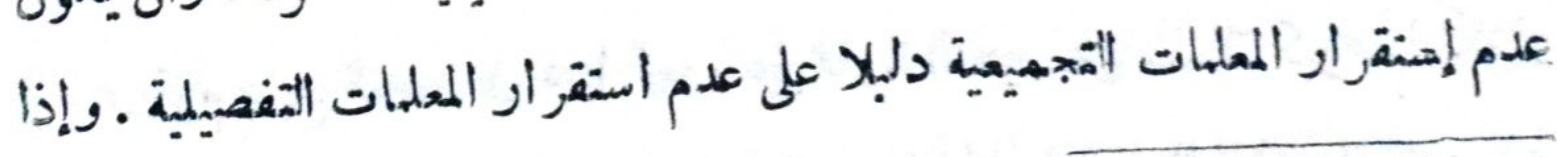

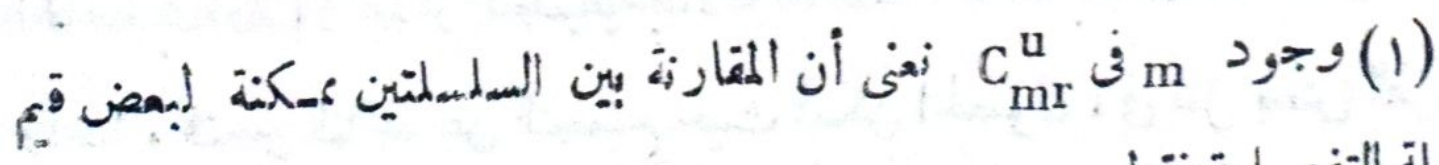
ألنسلة التفصيلية فتط 


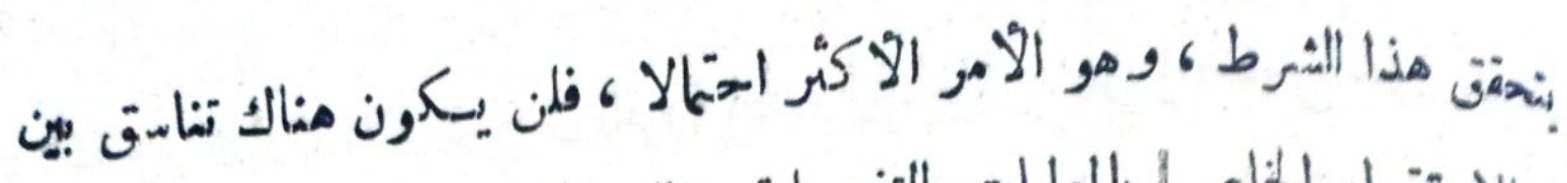

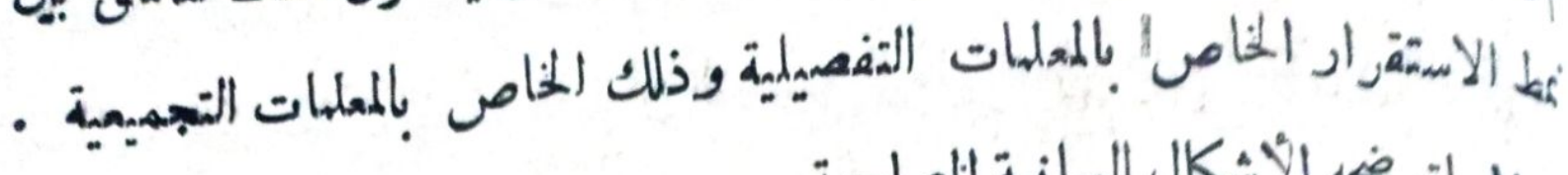
رهذا ماتوضيه الأشكال البيها انية المصاحبة .

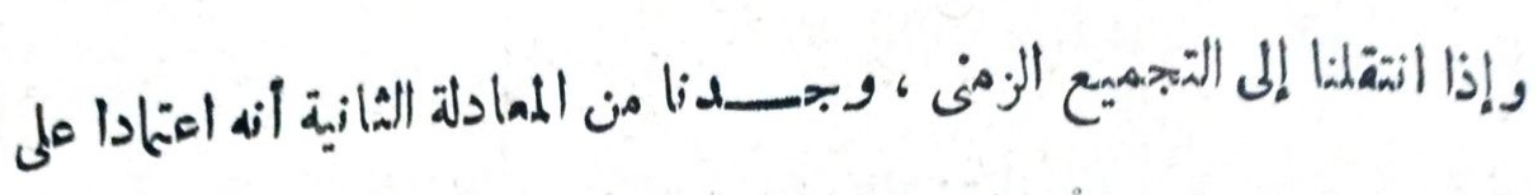
ما إذا كان المثتصر

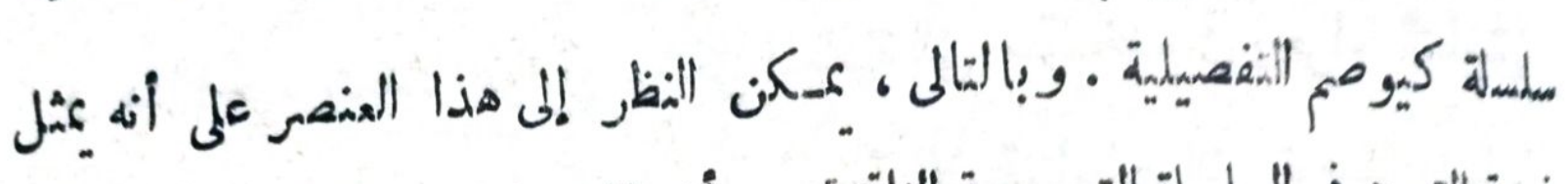

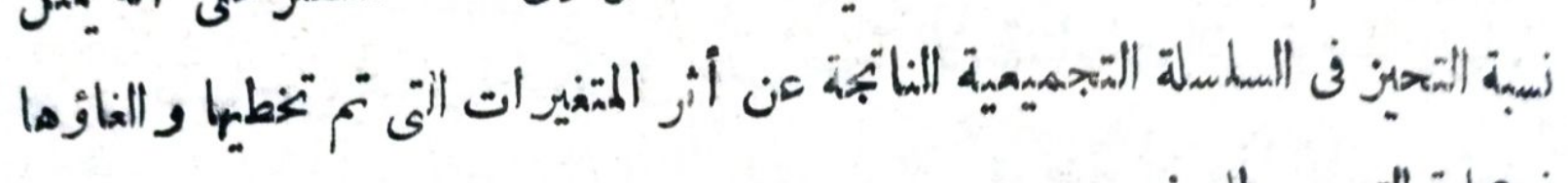
فن علية التجميع الزهنى -

ومن الجدير بالملاحظة أنه فن هالة النوذج البسيط النى لايكتوى على أية

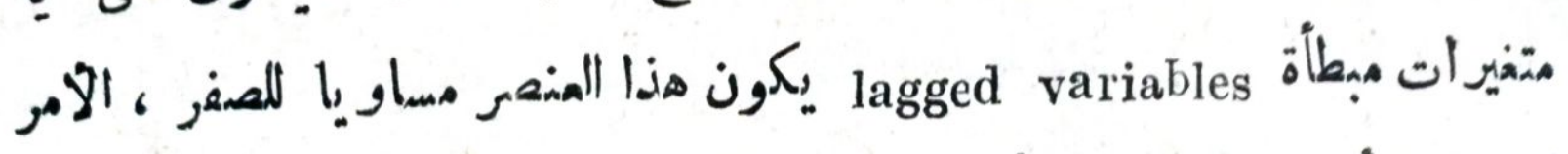

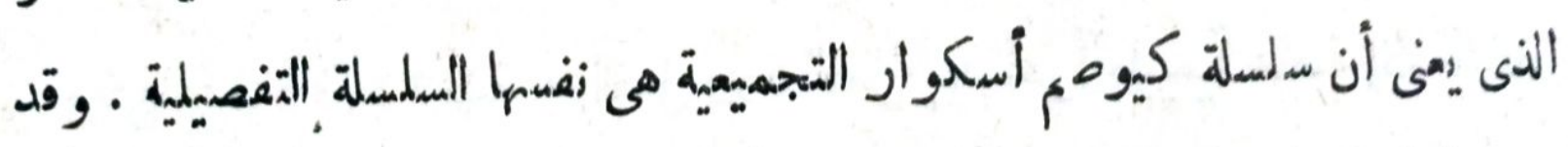

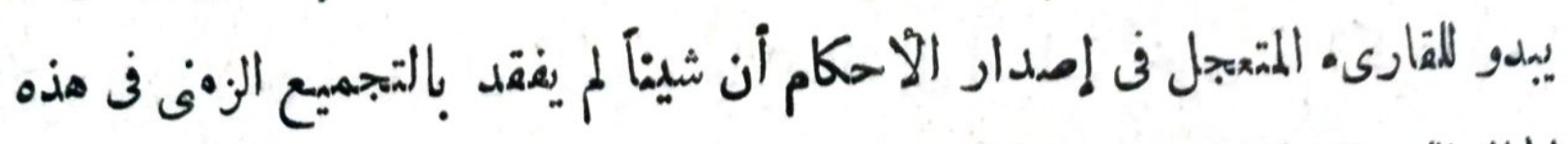

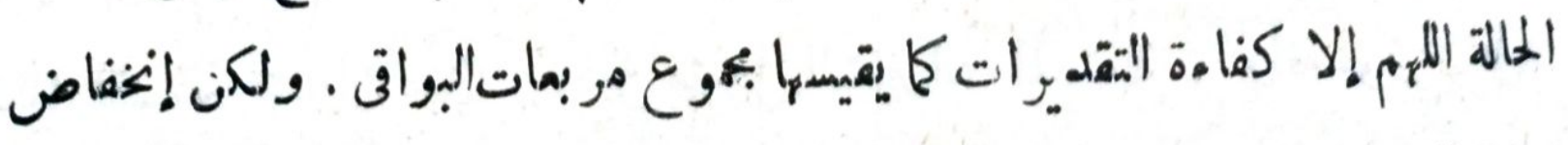

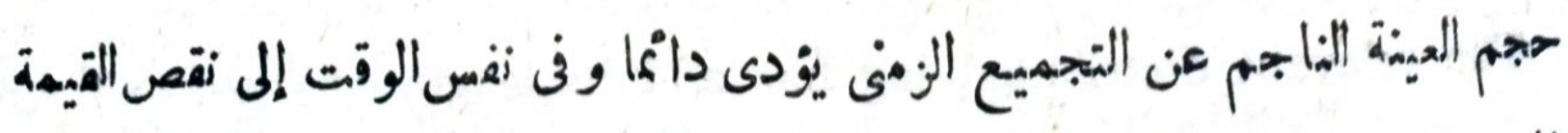

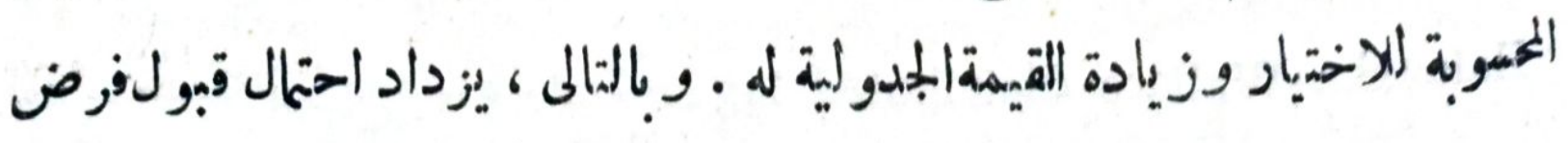

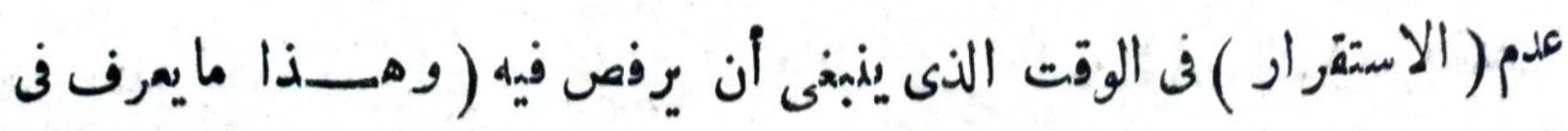

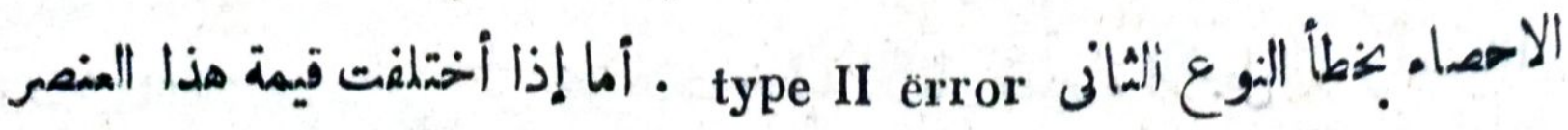

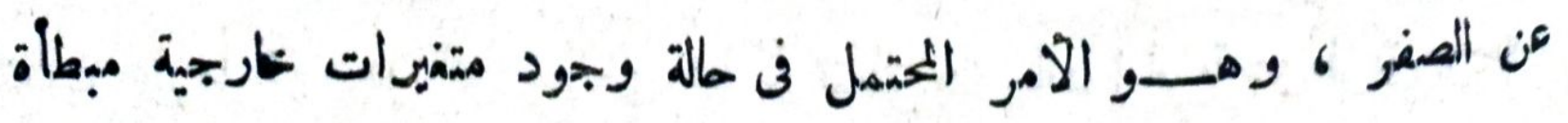
اليم agged exogenous variables الحسوبة من السلسلة المجهميهية أكبر . ومع ذاك ، فلا يزال مسكنا أن نمجز مذه. 


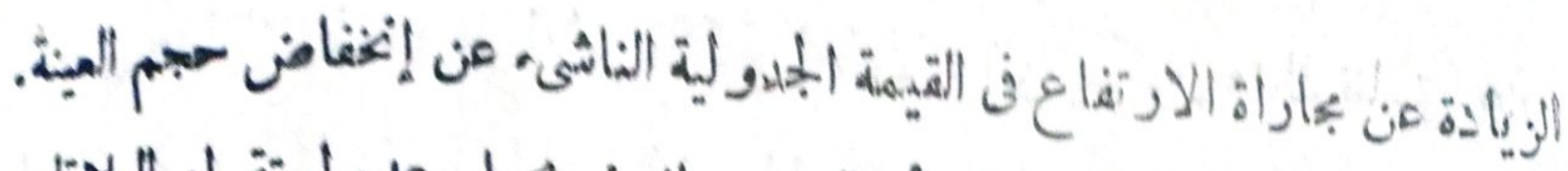

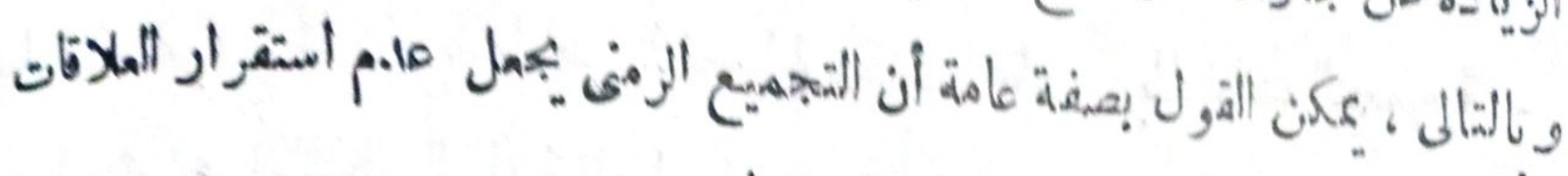
ألدالية أقل وضوحأ ، وقد يكوله إلى استقراد •

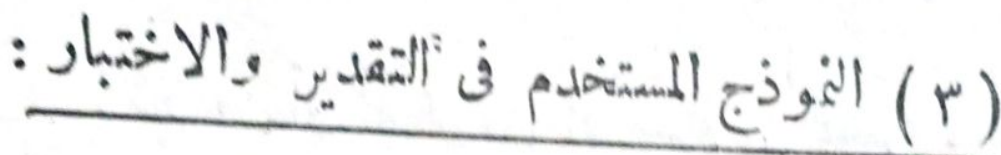

في هذا الجزم. يتهدد التموذج وششكل المهادلة التى ستسخدم في إجراء التطبيق

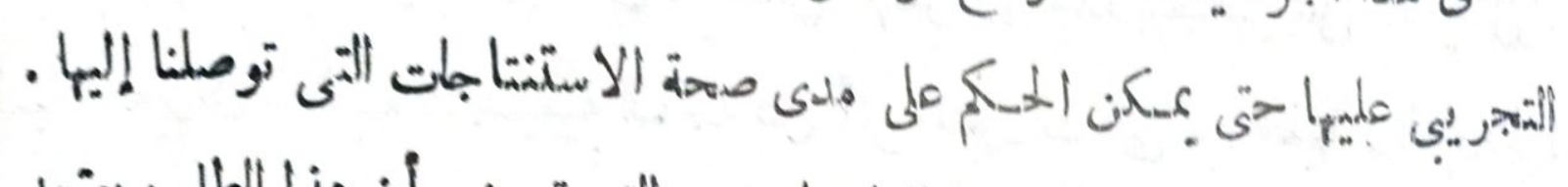

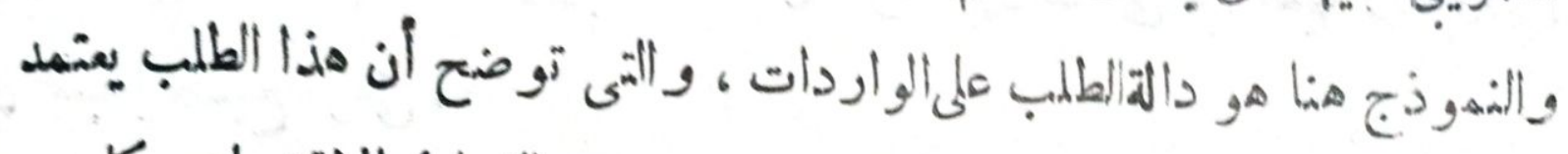

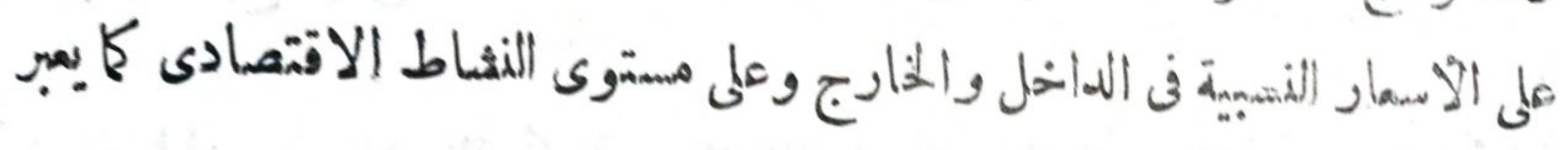
عنه الدنّل القوىى .

ولان وجود فترة زمنية بين الفهل ورد الفهل يعد أهراً طبيعياً خاصة إذا كانت

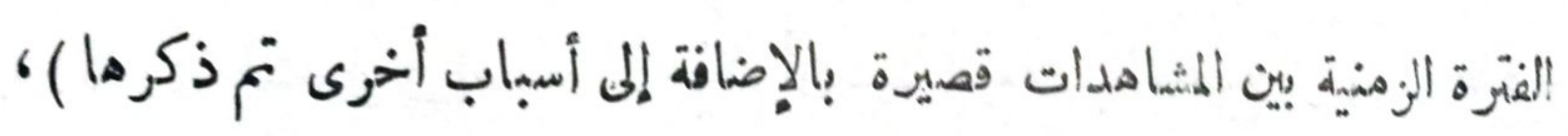

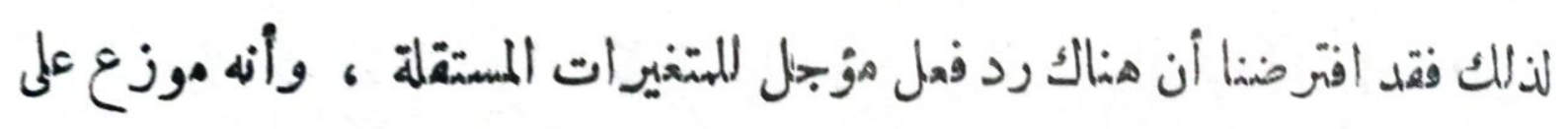

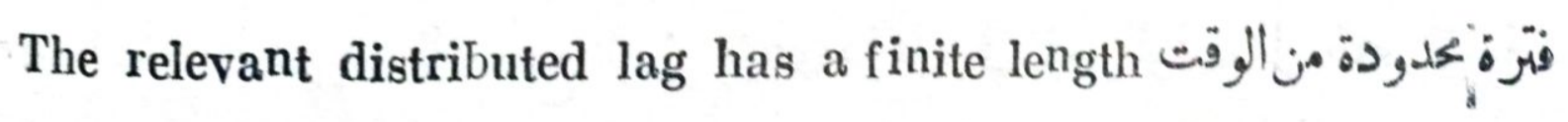

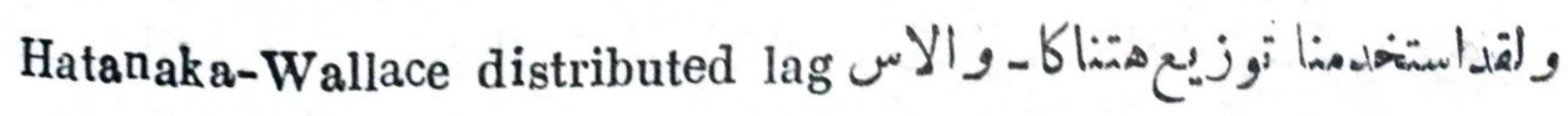

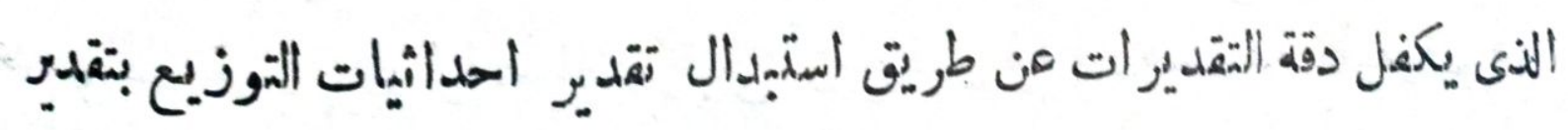

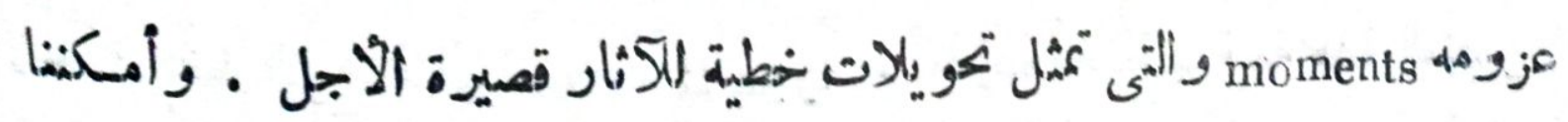

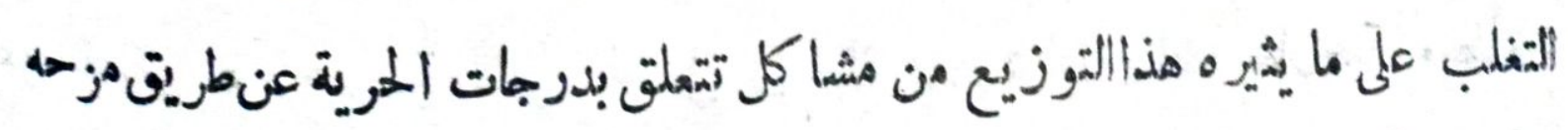

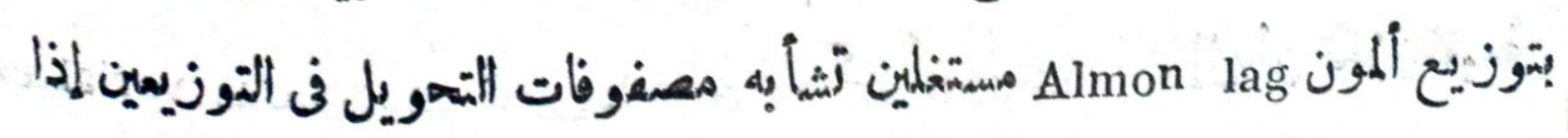
مانوافرتش شروط مaينة . 


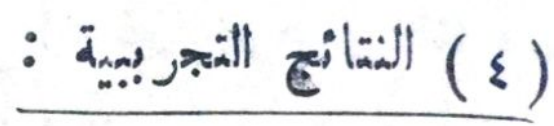

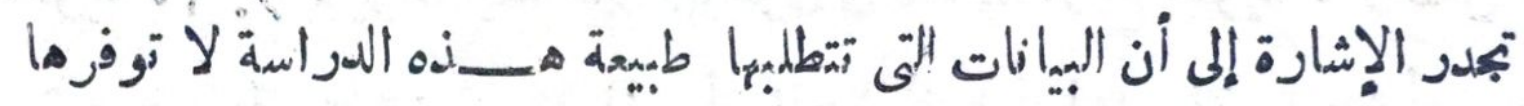

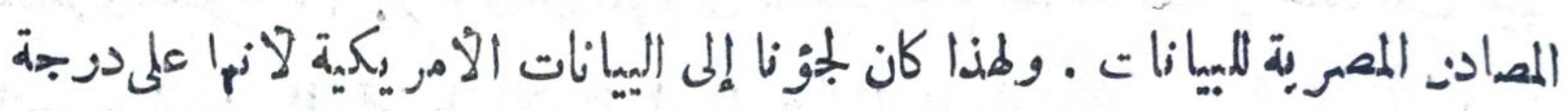

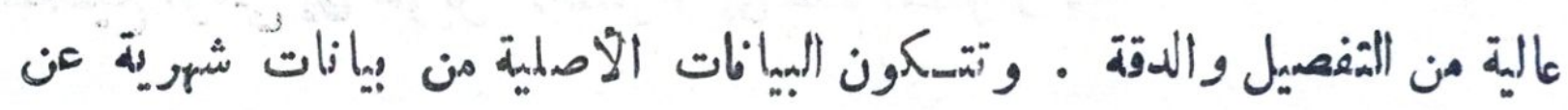

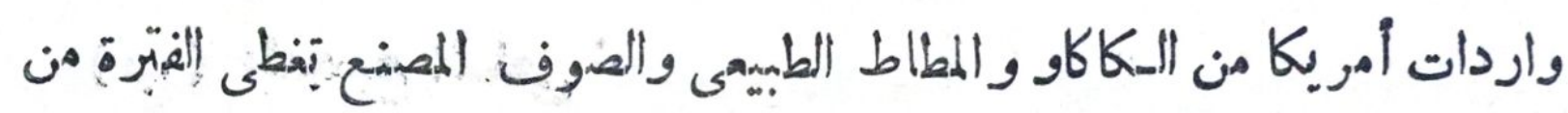

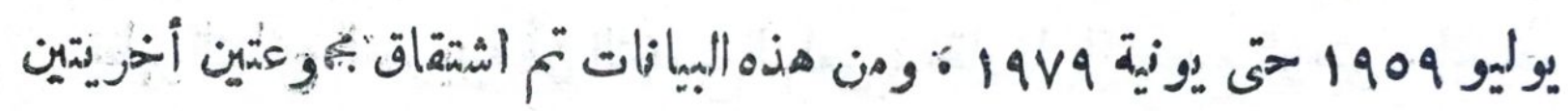

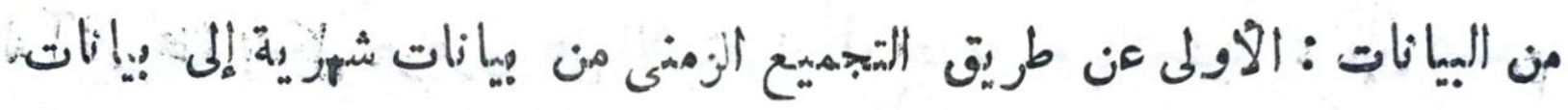

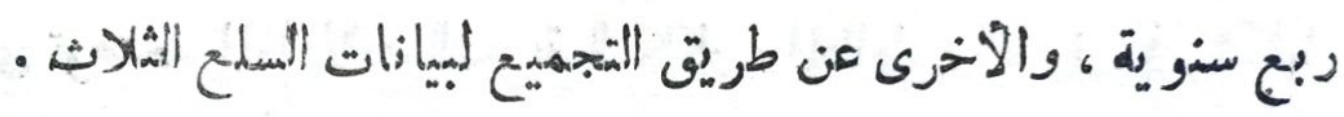

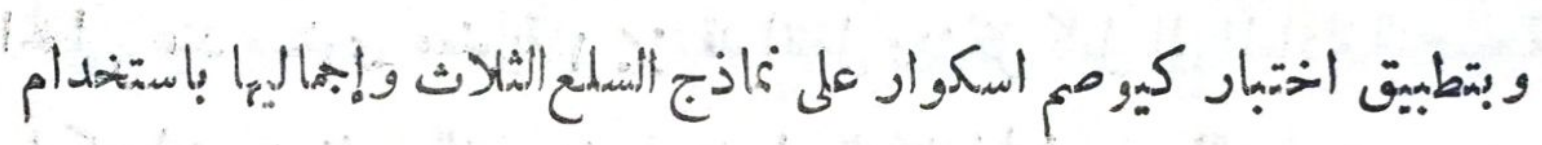

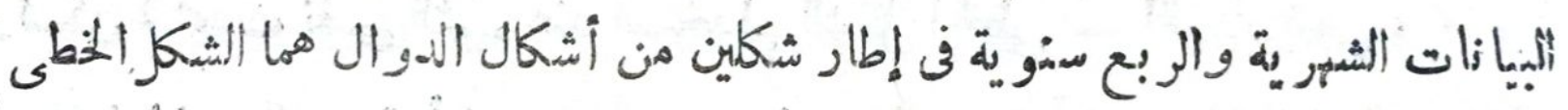
والخطى - اللوغاريتهى linear and log - linear functional forms أمكن

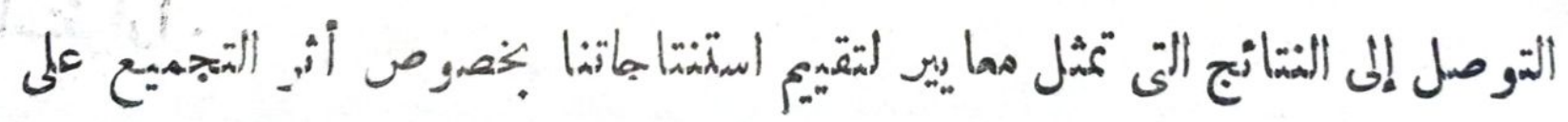

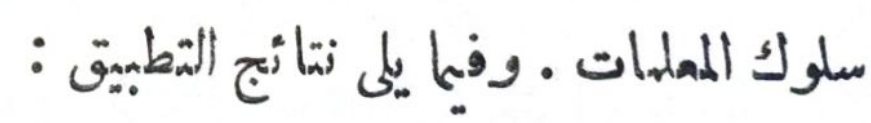

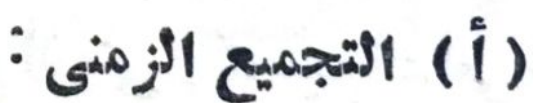

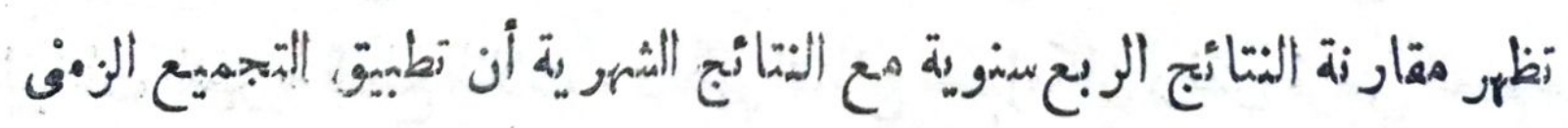

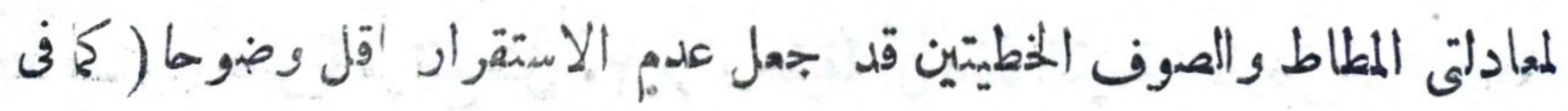

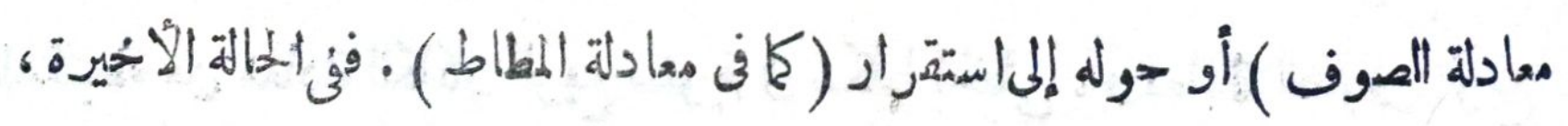

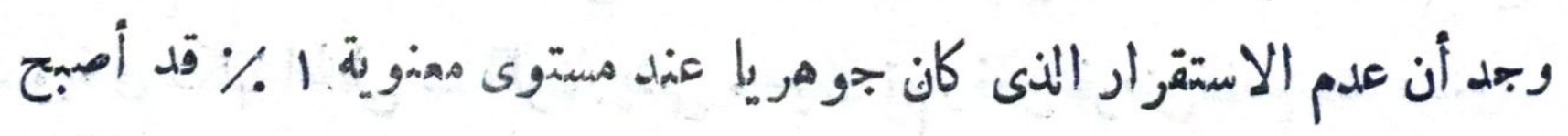

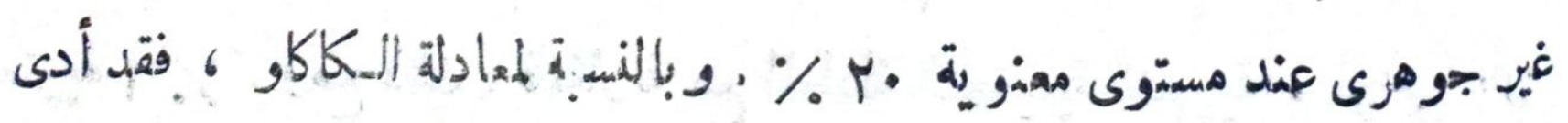

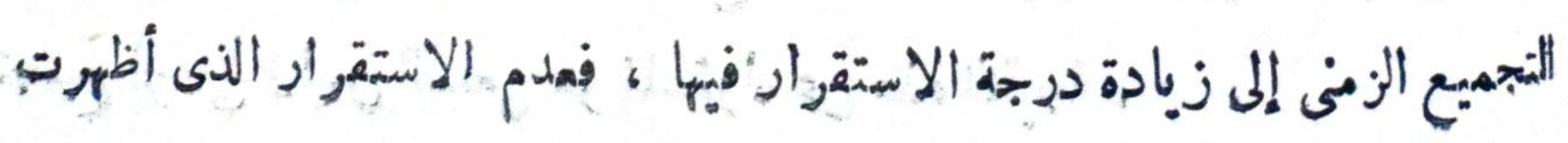




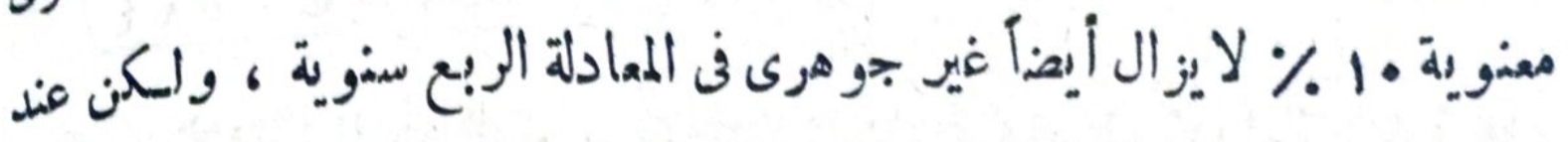

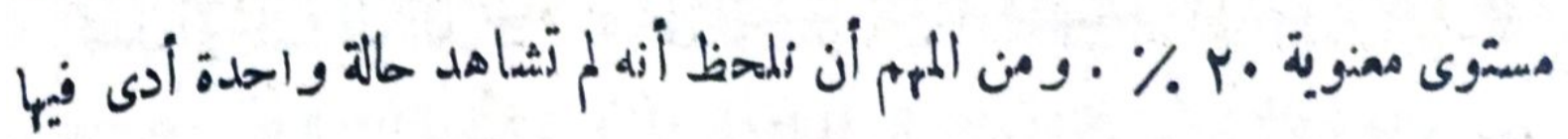

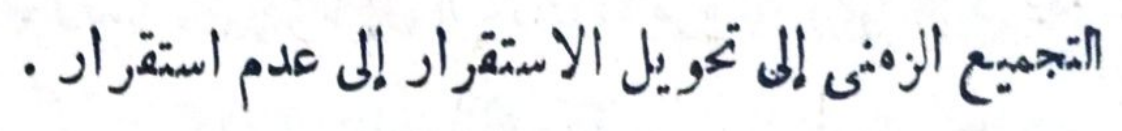

\section{(ب) الثجميع السلعى :}

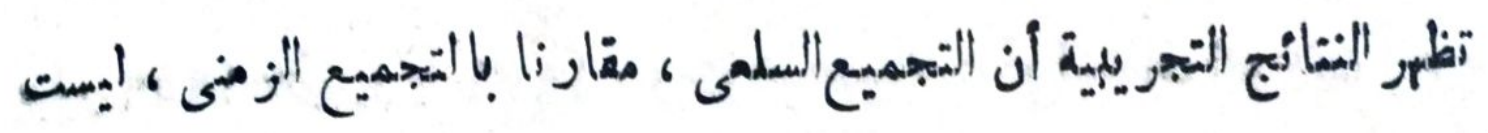

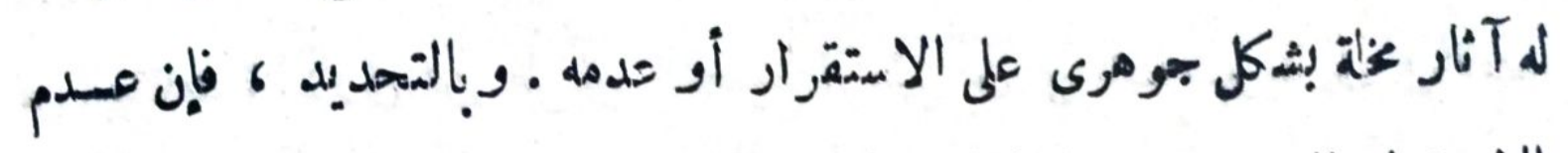

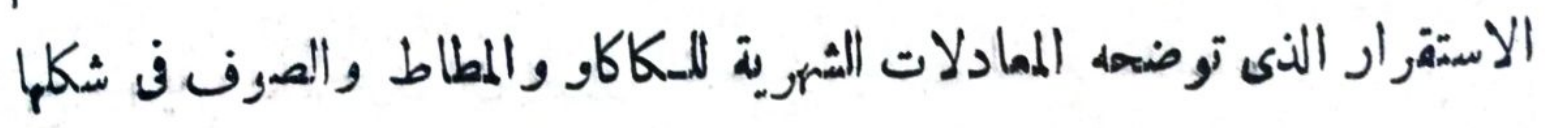

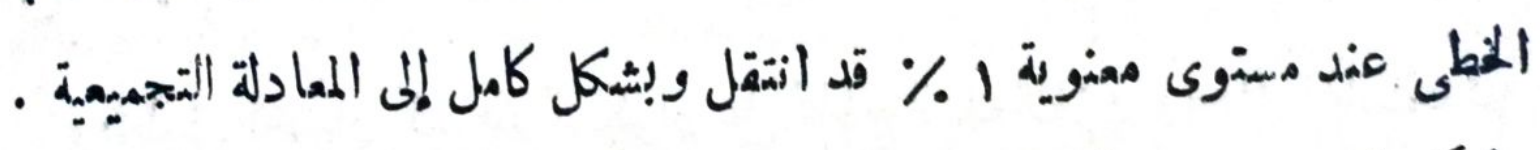

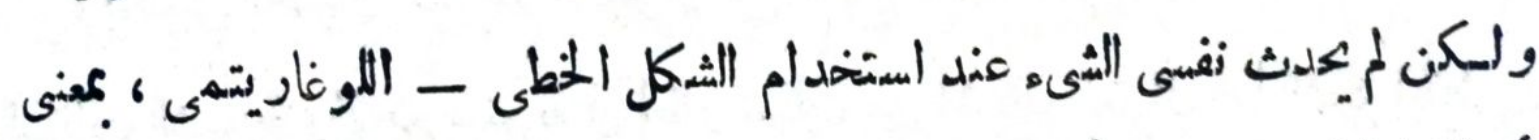

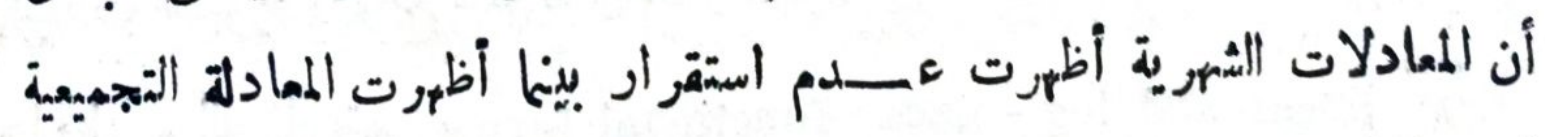
استترارا.

\section{(ج) ( ) التجميع المركب :}

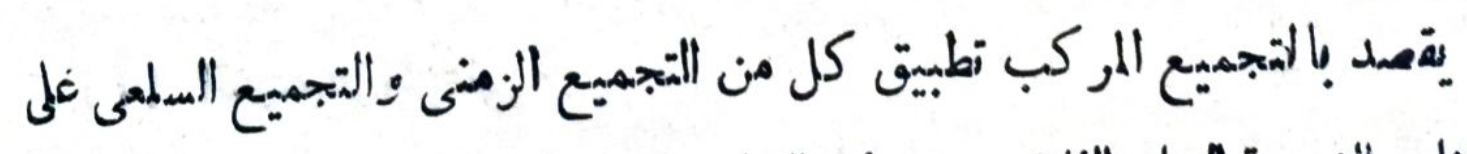

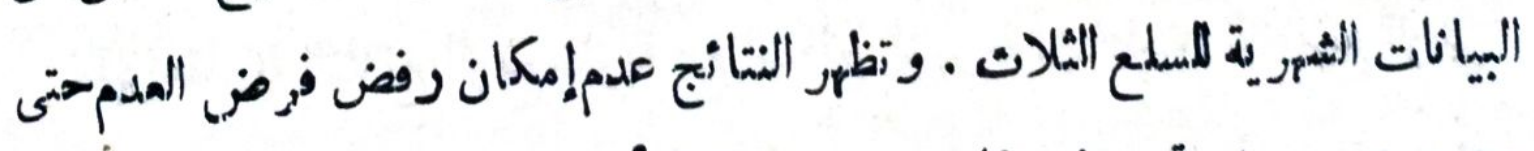

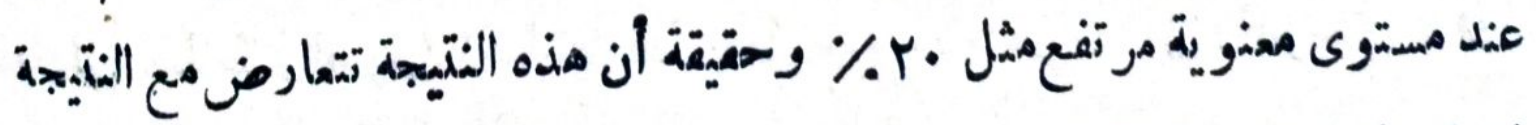

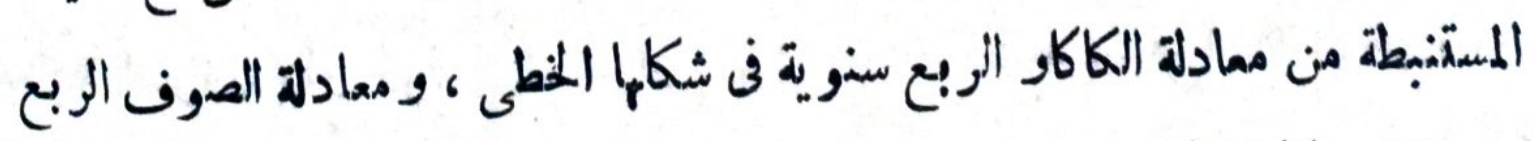

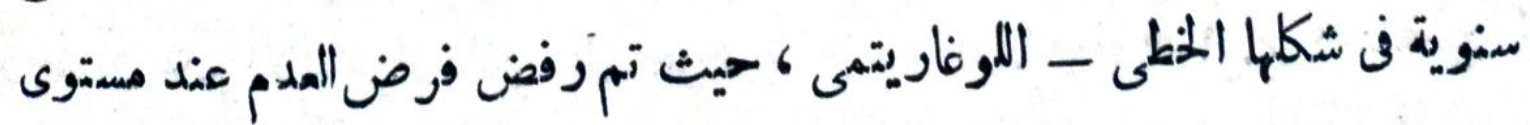

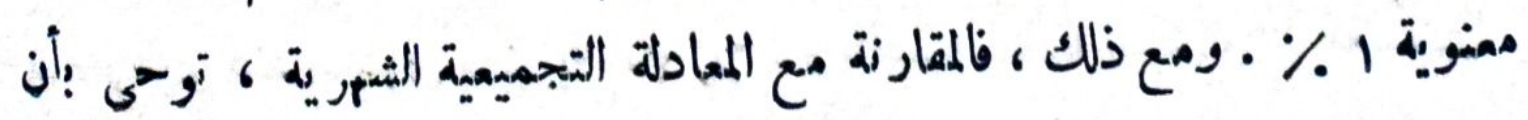

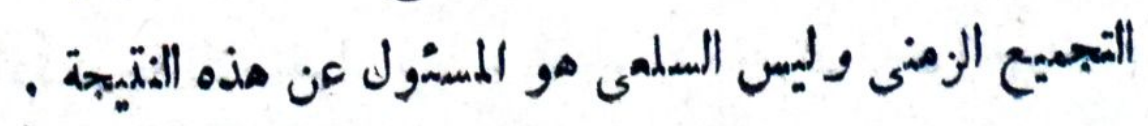




\section{: (•)}

على المستوى التجرييى الأكثر خصوصية أت المتتانج مز كدة ما توصلمنا إلم

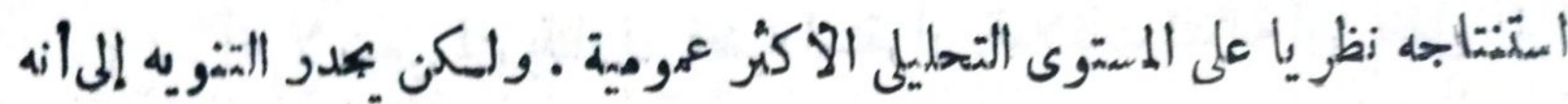

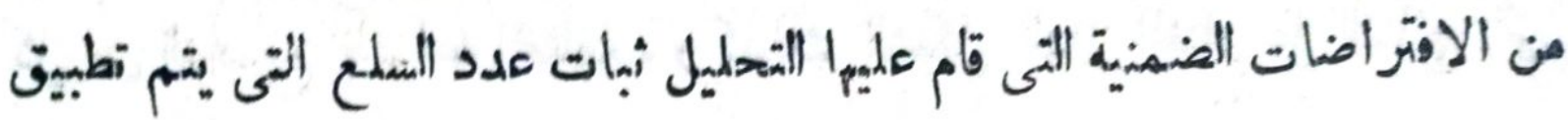

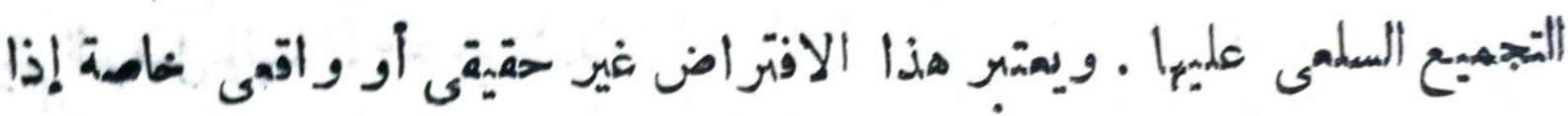

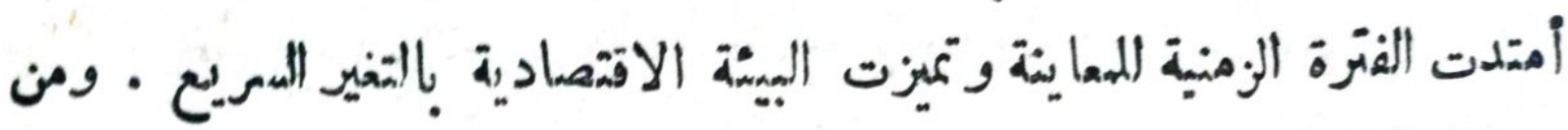

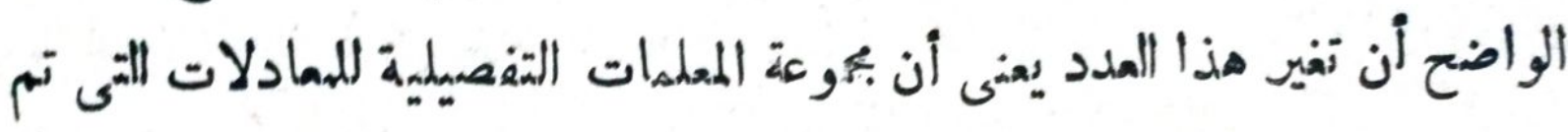

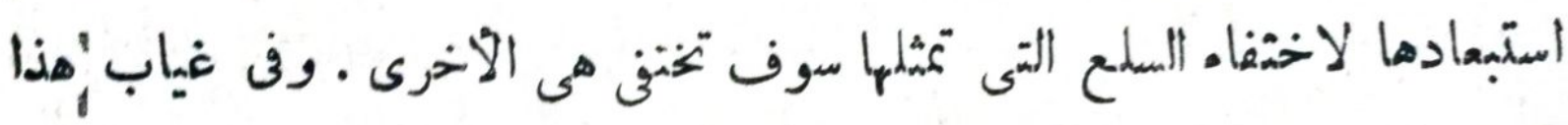

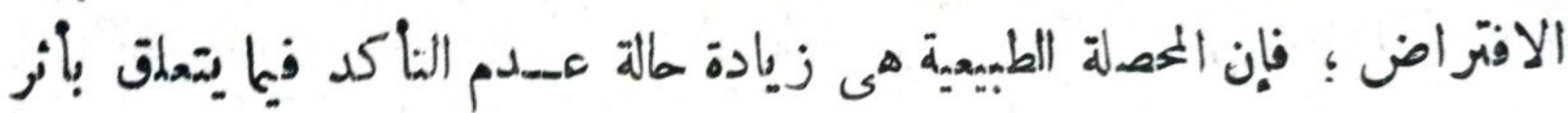

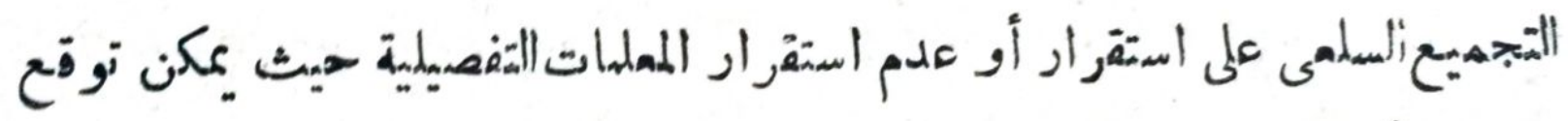
حدوث أى شى. . ـ وتختم هذه الدراسة بالتر كيز على الثقاط التيالية :

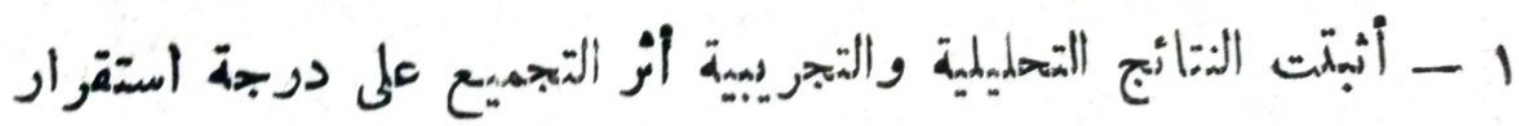

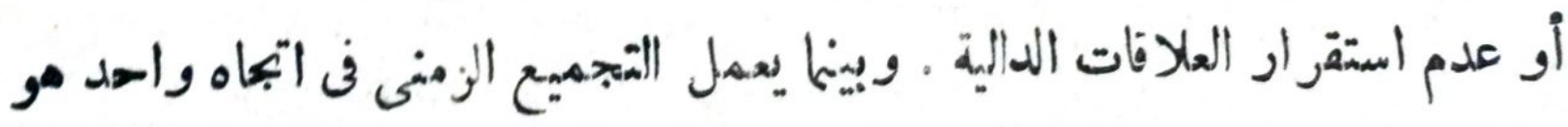

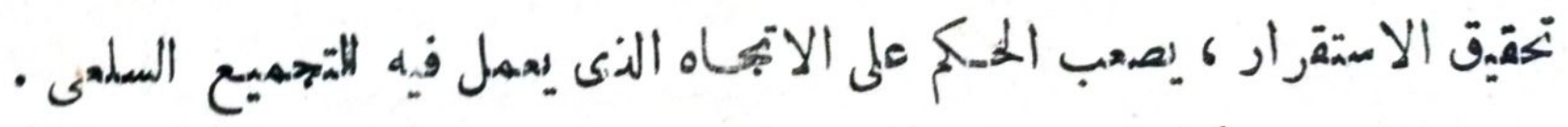
وإن كن يلاحظظ أنه إذا حدث و كان مدامل الارتباط بين كل سلمتيّن مستقل

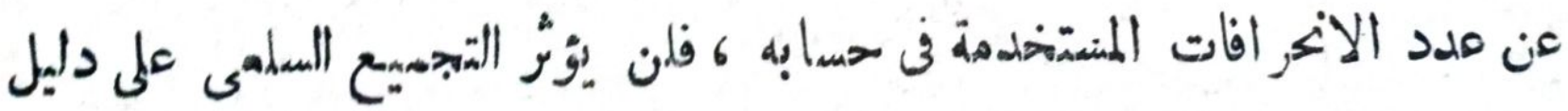

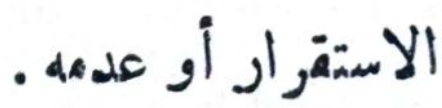

r - تدل مقار نة المتانج المتحصل علميها في ظســل المهادلات الخطية بتك

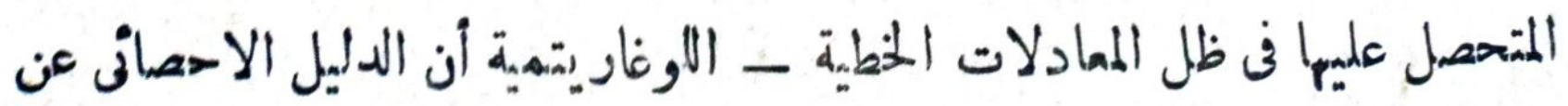

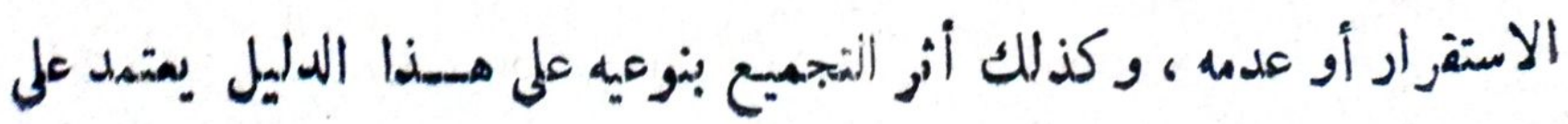


الثكل الدالى الذى تأخده مهادلة الانحدار ـ. وتظهر المتانج أن التحويل اللوغاريتشى

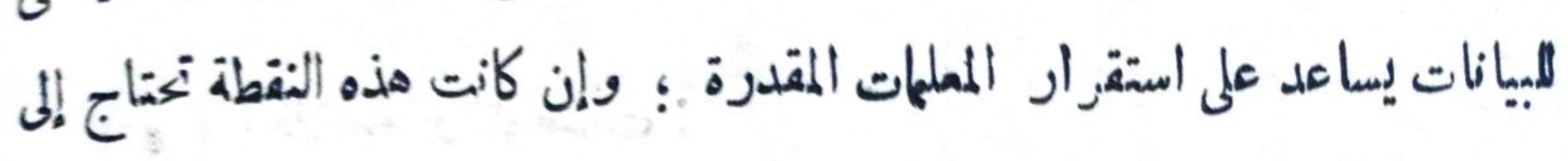
مزيد من البهث .

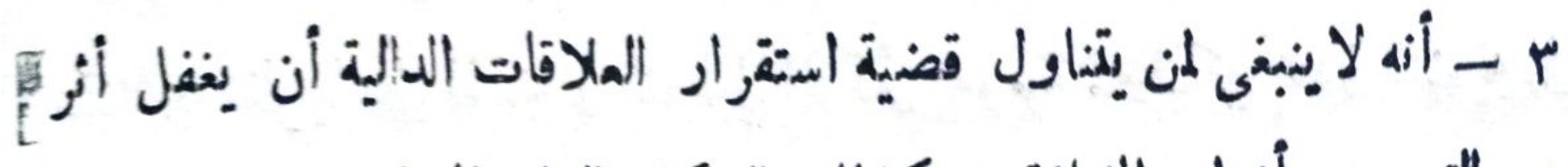

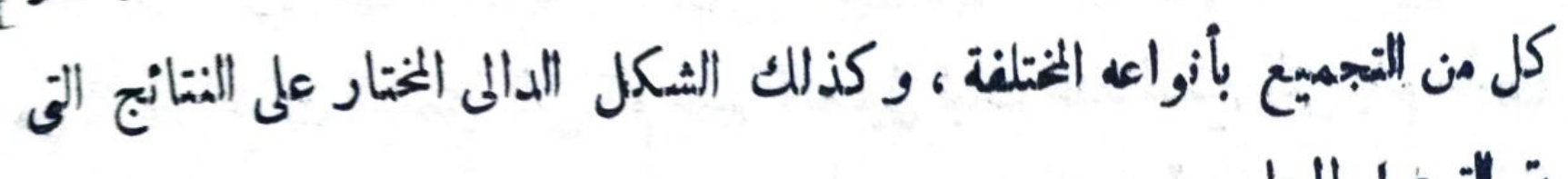

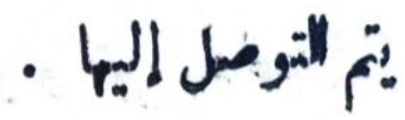

